\title{
Advanced Treatment of Pesticide-Containing Wastewater Using Fenton Reagent Enhanced by Microwave Electrodeless Ultraviolet
}

\author{
Gong Cheng, ${ }^{1}$ Jing Lin, ${ }^{1}$ Jian Lu, ${ }^{1}$ Xi Zhao, ${ }^{1}$ Zhengqing Cai, ${ }^{2}$ and Jie Fu ${ }^{3}$ \\ ${ }^{1}$ Shenzhen Academy of Environmental Sciences, Shenzhen 518001, China \\ ${ }^{2}$ Environmental Engineering Program, Department of Civil Engineering, Auburn University, Auburn, AL 36849, USA \\ ${ }^{3}$ School of Civil and Environmental Engineering, Georgia Institute of Technology, Atlanta, GA 30332, USA \\ Correspondence should be addressed to Zhengqing Cai; zzc0008@tigermail.auburn.edu and Jie Fu; jie.fu@ce.gatech.edu
}

Received 17 February 2015; Revised 21 April 2015; Accepted 21 April 2015

Academic Editor: Qaisar Mahmood

Copyright (C) 2015 Gong Cheng et al. This is an open access article distributed under the Creative Commons Attribution License, which permits unrestricted use, distribution, and reproduction in any medium, provided the original work is properly cited.

\begin{abstract}
The photo-Fenton reaction is a promising method to treat organic contaminants in water. In this paper, a Fenton reagent enhanced by microwave electrodeless ultraviolet (MWEUV/Fenton) method was proposed for advanced treatment of nonbiodegradable organic substance in pesticide-containing biotreated wastewater. MWEUV lamp was found to be more effective for chemical oxygen demand (COD) removal than commercial mercury lamps in the Fenton process. The pseudo-first order kinetic model can well describe COD removal from pesticide-containing wastewater by MWEUV/Fenton, and the apparent rate constant (k) was $0.0125 \mathrm{~min}^{-1}$. The optimal conditions for MWEUV/Fenton process were determined as initial $\mathrm{pH}$ of $5, \mathrm{Fe}^{2+}$ dosage of $0.8 \mathrm{mmol} / \mathrm{L}$, and $\mathrm{H}_{2} \mathrm{O}_{2}$ dosage of $100 \mathrm{mmol} / \mathrm{L}$. Under the optimal conditions, the reaction exhibited high mineralization degrees of organics, where COD and dissolved organic carbon (DOC) concentration decreased from $183.2 \mathrm{mg} / \mathrm{L}$ to $36.9 \mathrm{mg} / \mathrm{L}$ and $43.5 \mathrm{mg} / \mathrm{L}$ to $27.8 \mathrm{mg} / \mathrm{L}$, respectively. Three main pesticides in the wastewater, as Dimethoate, Triazophos, and Malathion, were completely removed by the MWEUV/Fenton process within $120 \mathrm{~min}$. The high degree of pesticides decomposition and mineralization was proved by the detected inorganic anions.
\end{abstract}

\section{Introduction}

The widespread use of pesticides in the past decades represents serious water pollutants [1]. Various types of pesticides residues were frequently detected in surface water and aroused great public concern. The pesticides will cause potential adverse health risks even at low concentration (pg/L to ng/L) [2]. These pesticides, retained in agrochemical wastewater, are resistant to conventional biological treatment owing to their high toxicity and biological persistence. It was reported that no significant decrease in pesticide content occurred after the biological treatment and remaining recalcitrant organic carbon mainly due to pesticide molecules [3].

Advanced oxidation processes (AOPs) were expected to decompose those typically stable products into carbon dioxide, water, and inorganics or, at least, transform them into harmless compounds [4]. AOPs have been successfully applied for the removal of recalcitrant substances from organic wastewater in recent years [5-8]. Among AOPs, photo-Fenton is considered as a promising process to generate oxidizing species for pollutants degradation $[9,10]$. Photo-Fenton reaction requires the presence of $\mathrm{Fe}^{2+}$ and hydrogen peroxide under the UV radiation to produce highly oxidative hydroxyl radicals which react with the organic pollutants and lead to the complete mineralization [11]. PhotoFenton is effective in treating wastewater with various organic contaminants, such as dye [12], 2,4-dichlorophenol [13], and nonylphenol polyethoxylate [14]. It has been concluded that the introduction of UV light significantly promotes the degradation efficiency by photoreducing $\mathrm{Fe}^{3+}$ to $\mathrm{Fe}^{2+}$ and producing additional hydroxyl radicals. Thus, UV light source is a crucial design of photo-Fenton reactor. 
Microwave electrodeless ultraviolet (MWEUV) was a new-type UV light source developed in recent years $[15,16]$. It includes a mercury vapor lamp powered by microwave energy and emitted stable UV radiation. The MWEUV lamp would lead to a further development of simple and high efficiency photochemical reactor owing to its unique advantages [17-19]: high UV radiant power, long lifetime, and being immersed into reaction solution with adaptable lamp shapes. Particularly, both UV and microwave radiations are available simultaneously by using microwave energy. Many studies have reported successful applications of MWEUV lamp as light source in photolysis [20], $\mathrm{UV} / \mathrm{H}_{2} \mathrm{O}_{2}$ [21], and heterogeneous or homogeneous photocatalysis processes [22-24] for organic wastewater treatment. It has been proved that the simultaneous application of microwave power and UV light exhibits higher efficiency in photochemical processes.

In recent years, several advanced oxidation processes for the treatment of pesticide-containing wastewater have been proposed. However, the degradation efficiency for recalcitrant pesticide substances did not meet the demand of commercial application. In this research, the MWEUV lamp was employed for enhancing Fenton process to remove nonbiodegradable organic pesticide in pesticide-containing effluent after biotreatment. Optimal parameters for COD removal by the MWEUV/Fenton process were determined. Oxidation degree and mineralization performance of residual pesticide in wastewater were also evaluated in terms of average oxidation state (AOS), carbon oxidation state (COS), DOC, and inorganic anions concentration.

\section{Experimental Methodology}

2.1. Materials and Reagents. Fresh wastewater was generated from pesticide container washing process in a chemical products estate (Guangdong, China). The sequential processes, coagulation, precipitation, and biodegradation, have been employed for elimination of suspended solids and biodegradable organic substances from the pesticidecontaining wastewater. Physical/chemical characteristics of fresh wastewater and the biotreated wastewater were showed in Table 1. The concentration of COD and pesticides in effluent wastewater without any advanced treatments still exceeded the discharge limits imposed by Discharge Limits of Water Pollutants (Local Standard: DB44/26-2001).

$\mathrm{H}_{2} \mathrm{O}_{2}\left(30 \%\right.$, w/w) and $\mathrm{FeSO}_{4} \cdot 7 \mathrm{H}_{2} \mathrm{O}$ were prepared at a predetermined concentration as Fenton reagent. $\mathrm{H}_{2} \mathrm{SO}_{4}$ $(1.0 \mathrm{mmol} / \mathrm{L})$ and $\mathrm{NaOH}(1.0 \mathrm{mmol} / \mathrm{L})$ were used for $\mathrm{pH}$ adjustment. All chemicals were of analytical grade, purchased from Sinopharm Chemical Reagent Co., Ltd (Shenzhen, China).

\subsection{Experimental Setup and Methods. A U-shaped MWEUV} lamp was used in this study. The lamp is made by quartz tubes filled with $1 \mathrm{mg}$ mercury and $0.66 \mathrm{kPa}$ argon. The external diameter is $20 \mathrm{~mm}$ and effective length is $250 \mathrm{~mm}$. The MWEUV lamp had prominent UV emission bands at 254, 313, 365, and $405 \mathrm{~nm}$. Microwave generator (Haier Co.
TABLE 1: Physical/chemical characteristics of fresh wastewater and the biotreated wastewater.

\begin{tabular}{|c|c|c|}
\hline $\begin{array}{l}\text { Concentration } \\
(\mathrm{mg} / \mathrm{L})\end{array}$ & Fresh wastewater & $\begin{array}{c}\text { Effluent after } \\
\text { biological treatment }\end{array}$ \\
\hline $\mathrm{pH}$ & $6.0 \sim 6.8$ & $\sim 7.0$ \\
\hline TSS & $618.85 \pm 70.90$ & $<15$ \\
\hline COD & $1540.34 \pm 202.12$ & $183.2 \pm 9.95$ \\
\hline $\mathrm{BOD}_{5}$ & $336.58 \pm 20.86$ & $<15$ \\
\hline $\begin{array}{l}\text { Dimethoate } \\
\left(\mathrm{C}_{5} \mathrm{H}_{12} \mathrm{NO}_{3} \mathrm{PS}_{2}\right)\end{array}$ & $15.66 \pm 3.38$ & $14.71 \pm 0.79$ \\
\hline $\begin{array}{l}\text { Triazophos } \\
\left(\mathrm{C}_{12} \mathrm{H}_{16} \mathrm{~N}_{3} \mathrm{O}_{3} \mathrm{PS}\right)\end{array}$ & $6.11 \pm 0.63$ & $5.87 \pm 0.89$ \\
\hline $\begin{array}{l}\text { Malathion } \\
\left(\mathrm{C}_{10} \mathrm{H}_{19} \mathrm{O}_{6} \mathrm{PS}_{2}\right)\end{array}$ & $31.65 \pm 4.77$ & $24.53 \pm 4.16$ \\
\hline
\end{tabular}

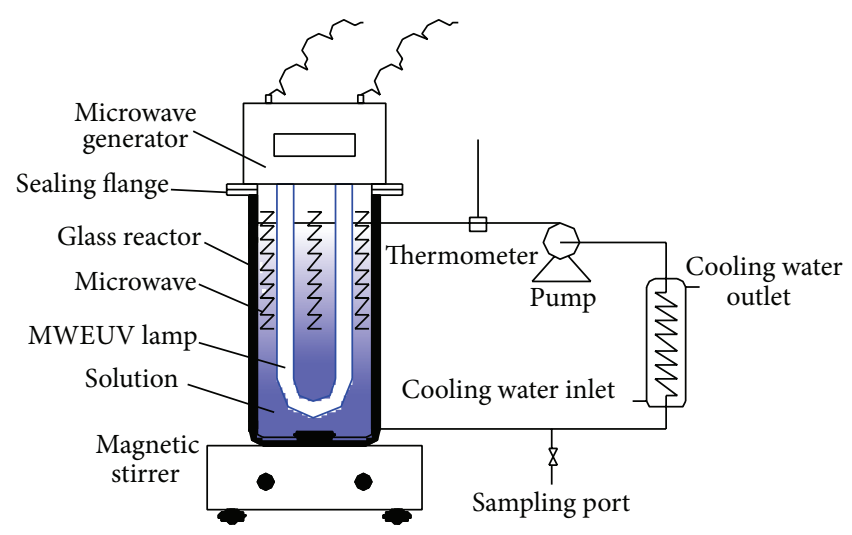

Figure 1: Schematic diagram of experimental setup.

Ltd, China) was operated with $80 \mathrm{~W}$ output at frequency of $2.45 \mathrm{GHz}$. The output power of MWEUV lamp was measured by monitoring the temperature of the solution with and without the MWEUV lamp [25]. According the calculation, approximate $40 \mathrm{~W}$ was supplied to excite MWEUV lamp and the rest power was consumed or converted to heat.

Schematic diagram of the experimental setup is shown in Figure $1.1000 \mathrm{~mL}$ pesticide-containing wastewater was added in the glass cylindrical reactor (available capacity of $1000 \mathrm{~mL}$ ). Then, required dosage of Fenton reagent was added into the solution and mixed by a magnetic stirrer ( $\mathrm{HJ}-3$, Jingda Instrument Company, China). Microwave generator was applied to excited MWEUV lamp emitting UV irradiation during the reaction. Solution temperature during the reaction was kept constant at $25 \pm 0.5^{\circ} \mathrm{C}$ by circulating solution to a cooler with a pump (DP-60, Seisun pumps Co., Ltd, China). Samples were withdrawn at predetermined time intervals, and the final $\mathrm{pH}$ values were adjusted to lower than 3 before analysis. All the runs were triplicated.

In this study, the experiments were carried out as follows and the results were compared: (1) Fenton oxidation run, (2) UV/Fenton run, assisted by a commercial UV mercury lamp (40 W of output, CREATOR, China), and (3) MWEUV/Fenton run, assisted by MWEUV lamp. 
2.3. Analytical Methods. The $\mathrm{pH}$ value of solution was measured using a $\mathrm{pH}$ meter (PHB-5, INESA Instrument, China). Total suspended solids (TSS) were measured by gravimetry method. Chemical oxygen demand (COD) was determined according to the Standard Methods [26]. Dissolved organic carbon (DOC) was measured by TOC analyzer (Multi N/C, Jena). $\mathrm{NO}_{3}{ }^{-}, \mathrm{SO}_{4}{ }^{2-}$, and $\mathrm{PO}_{4}{ }^{3-}$ were quantified by ion chromatography (Dionex ICS-900; column Ion Pac AS23; suppressor MMS 300). Isocratic elution was done with $\mathrm{KOH}$ solution, at a flow rate of $1.0 \mathrm{~mL} / \mathrm{min}$, for anions analyzed. The quantitative analysis of pesticides was performed by GC/MS (Agilent, 6890N-5975B). Samples were subsequently injected in GC, coupled with a mass spectrometer. The mass detector was operated in MRM (Multiple Reaction Monitoring) mode, selecting specific transitions for each pesticide. The final optimized method allowed the concurrent detection of three pesticides, during chromatographic runs of $20 \mathrm{~min}$.

\section{Results and Discussion}

3.1. Evaluation of Different Treatment Processes. PhotoFenton process produces hydroxyl radicals with powerful oxidizing ability to degrade organic pollution. The major reactions to form hydroxyl radicals are as follows [5]:

$$
\begin{gathered}
\mathrm{Fe}^{2+}+\mathrm{H}_{2} \mathrm{O}_{2} \longrightarrow \mathrm{Fe}^{3+}+\cdot \mathrm{OH}+\mathrm{OH}^{-} \\
\mathrm{Fe}^{3+}+\mathrm{H}_{2} \mathrm{O} \longrightarrow \mathrm{Fe}(\mathrm{OH})^{2+}+\mathrm{H}^{+} \\
\mathrm{Fe}(\mathrm{OH})^{2+} \stackrel{h v}{\longrightarrow} \mathrm{Fe}^{2+}+\cdot \mathrm{OH} \\
\mathrm{H}_{2} \mathrm{O}_{2} \stackrel{h v}{\longrightarrow} \cdot \mathrm{OH}+\cdot \mathrm{OH}
\end{gathered}
$$

In this study, treatment of pesticide-containing wastewater in different processes was evaluated. Specially, Fenton oxidation assisted by MWEUV and a commercial mercury UV lamp was compared. As shown in Figure 2, Fenton oxidation only achieved $48.7 \%$ of COD removal after $120 \mathrm{~min}$, while COD removal efficiency was significantly improved by introducing UV light. The COD concentration of pesticidecontaining wastewater with UV/Fenton treatment decreased $64.0 \%$. Such improvement was attributed to two facts: on the one hand, the reduction of $\mathrm{Fe}^{3+}$ (Equations (2), (3)) under $\mathrm{UV}$ irradiation regenerated $\mathrm{Fe}^{2+}$ that can further participate in the Fenton reaction and produce $\bullet \mathrm{OH}$ radicals. Such recycling enhanced the $\bullet \mathrm{OH}$ radical production and provides the UV/Fenton system sufficient activity for organic molecule decomposition. On the other hand, photolysis of $\mathrm{H}_{2} \mathrm{O}_{2}$ (Equation (4)) generates more $\mathrm{OH}$ radicals. It is also notable that MWEUV lamp as the light source is more effective in the Fenton system than a commercial mercury lamp. $72.1 \%$ of COD in wastewater was removed by MWEUV/Fenton treatment within $120 \mathrm{~min}$. In this experiment, wastewater temperature during the reaction was kept constant. It means that microwave irradiation accelerates chemical reactions by nonthermal effects such as polarization, dielectric properties, nuclear spin rotation, and spin alignment [27]. It was reported that simultaneous irradiation of microwave and UV-Vis light led to effective reactant decomposition

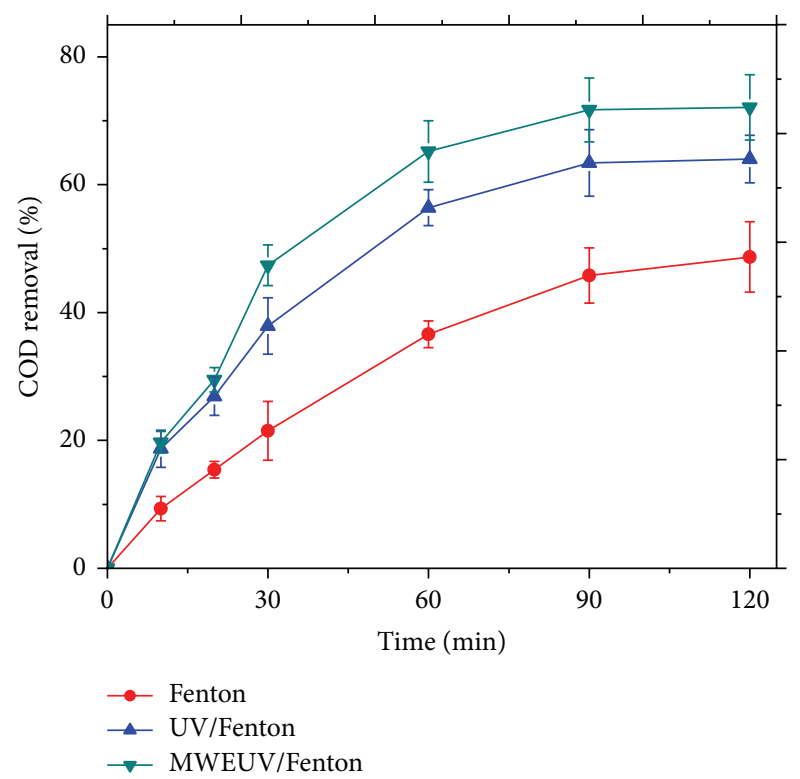

Figure 2: COD removal in different treatment processes. Experimental conditions: initial $\mathrm{pH}$ value of $5, \mathrm{H}_{2} \mathrm{O}_{2}$ dosage of $40 \mathrm{mmol} / \mathrm{L}$, and $\mathrm{Fe}^{2+}$ dosage of $0.6 \mathrm{mmol} / \mathrm{L}$.

by microwave ultraviolet electrodeless lamp introduced in photolysis, photocatalysis, and $\mathrm{UV} / \mathrm{H}_{2} \mathrm{O}_{2}$ systems $[25,27,28]$.

3.2. Effect of Initial $p H$ Value. The $\mathrm{pH}$ of wastewater is an important parameter for the MWEUV/Fenton process because it affects the decomposition of hydrogen peroxide [29] and the hydrolytic speciation of the ferric ion species [30]. To test the effect of initial $\mathrm{pH}$, experiments were carried out at initial $\mathrm{pH}$ ranging from 2 to 10; the results of COD removal by MWEUV/Fenton are shown in Figure 3(a). It is clear that removal efficiency is highly dependent on initial $\mathrm{pH}$, and the optimum $\mathrm{pH}$ is between 2 and 4. The COD removal efficiency decreased from $73.8 \%$ to $41.7 \%$ according to the increase of $\mathrm{pH}$ from 5 to 9 . Many researchers have also reported the optimum $\mathrm{pH}$ as 3-5 for conventional Fenton or photo-Fenton processes [31-33]. Neamtu et al. [34] summarized various photoactive species of iron formed at different $\mathrm{pH}$ conditions. The dominant species at $\mathrm{pH} 1-2$ is $\mathrm{Fe}\left[\mathrm{H}_{2} \mathrm{O}\right]_{6}{ }^{3+}$, 2-3 is for $\mathrm{Fe}[\mathrm{OH}]\left[\mathrm{H}_{2} \mathrm{O}_{5}{ }^{2+}\right.$, and 3-4 is for $\mathrm{Fe}[\mathrm{OH}]_{2}\left[\mathrm{H}_{2} \mathrm{O}\right]_{4}{ }^{+}$. $\mathrm{Fe}(\mathrm{OH})^{2+}$ species is reported to have the highest photoreactivity in Fenton's oxidation [35]. At acidic $\mathrm{pH}, \mathrm{Fe}^{3+}$ hydroxyl complexes are highly soluble and $\mathrm{Fe}(\mathrm{OH})^{2+}$ is the predominant form of the $\mathrm{Fe}^{3+}$ hydroxyl complexes. At higher $\mathrm{pH}$, the concentration of $\mathrm{Fe}[\mathrm{OH}]^{2+}$ complex ions in solution decreased with the precipitation of ferrous ion as oxyhydroxides [36]. Under the alkaline solution condition, the removal of pollutant is mainly attributed to adsorption and coagulation rather than Fenton oxidation [37].

3.3. Effect of $\mathrm{H}_{2} \mathrm{O}_{2}$ Dosage. Effect of $\mathrm{H}_{2} \mathrm{O}_{2}$ dosage on $\mathrm{COD}$ removal from pesticide-containing wastewater by MWEUV/Fenton is shown in Figure 3(b). As expected, 


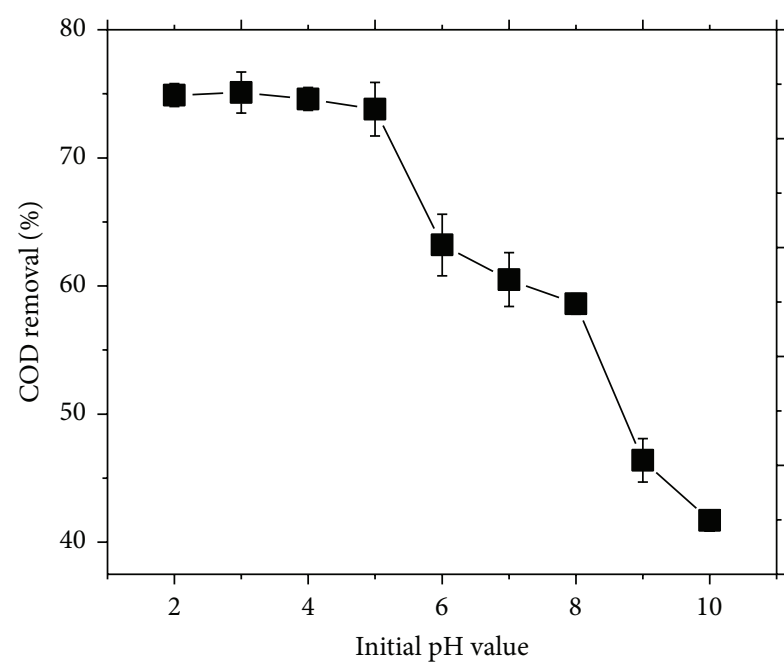

(a)

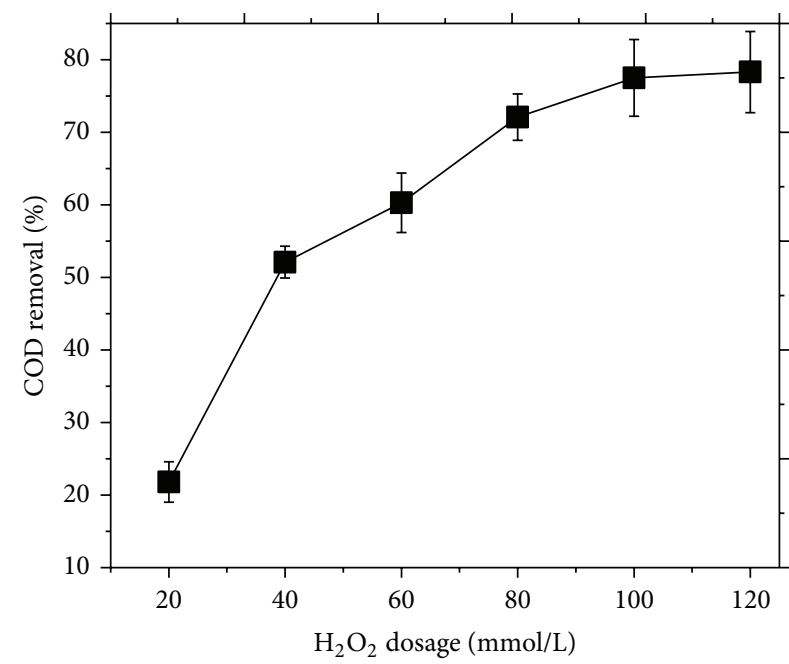

(b)

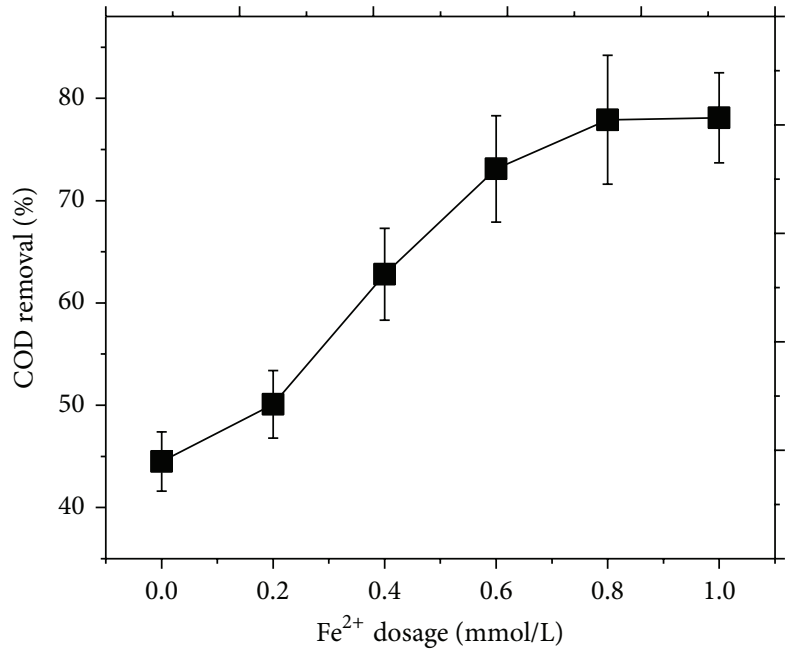

(c)

FIGURE 3: Effect of (a) initial pH value with $\mathrm{H}_{2} \mathrm{O}_{2}$ dosage of $40 \mathrm{mmol} / \mathrm{L}$, (b) $\mathrm{H}_{2} \mathrm{O}_{2}$ dosage, and (c) $\mathrm{Fe}^{2+}$ dosage with $\mathrm{H}_{2} \mathrm{O}_{2}$ dosage of 100 mmol/L on COD removal. General experimental parameters: initial $\mathrm{pH}$ value of 5, $\mathrm{Fe}^{2+}$ dosage of $0.6 \mathrm{mmol} / \mathrm{L}$, and reaction time of $120 \mathrm{~min}$.

the increase of $\mathrm{H}_{2} \mathrm{O}_{2}$ dosage from 20 to $80 \mathrm{mmol} / \mathrm{L}$ accelerated COD removal. The increased degradation efficiency can be attributed to the additional $\mathrm{OH}$ radicals produced from $\mathrm{H}_{2} \mathrm{O}_{2}$ decomposition. However, $\mathrm{COD}$ removal could not be obviously improved by excessive addition of $\mathrm{H}_{2} \mathrm{O}_{2}$ $(>100 \mathrm{mmol} / \mathrm{L})$. The results showed a negligible increase from $77.5 \%$ to $78.3 \%$ in removal efficiency when $\mathrm{H}_{2} \mathrm{O}_{2}$ dosage further increased from 100 to $120 \mathrm{mmol} / \mathrm{L}$. It can be interpreted that the excessive $\mathrm{H}_{2} \mathrm{O}_{2}$ acts as a scavenger of $\bullet \mathrm{OH}$, but the produced $\mathrm{HO}_{2}$ • (Equations (5)-(7)) has much lower oxidation capacities [38]. Therefore, the optimum $\mathrm{H}_{2} \mathrm{O}_{2}$ dosage was found to be $100 \mathrm{mmol} / \mathrm{L}$ for advanced treatment of the pesticide-containing wastewater by the MWEUV/Fenton:

$$
\begin{aligned}
& \mathrm{H}_{2} \mathrm{O}_{2}+\cdot \mathrm{OH} \longrightarrow \mathrm{HO}_{2} \bullet+\mathrm{H}_{2} \mathrm{O} \\
& \mathrm{HO}_{2} \cdot+\mathrm{OH} \longrightarrow \mathrm{H}_{2} \mathrm{O}+\mathrm{O}_{2} \\
& \bullet \mathrm{OH}+\cdot \mathrm{OH} \longrightarrow \mathrm{H}_{2} \mathrm{O}_{2}
\end{aligned}
$$

Li et al. [39] investigated catechol oxidation in nano$\mathrm{Fe}_{3} \mathrm{O}_{4}$ catalyzing UV-Fenton process. The best operational $\mathrm{H}_{2} \mathrm{O}_{2}$ dosage was determined to obtain high efficiency of both $\mathrm{H}_{2} \mathrm{O}_{2}$ utilization and COD removal. Lucas and Peres [40] observed the decreasing dye decolorization at excessive $\mathrm{H}_{2} \mathrm{O}_{2}$ concentration $(>2 \mathrm{mmol} / \mathrm{L}$ ) for Reactive Black 5 in Fenton/UV-C and ferrioxalate $/ \mathrm{H}_{2} \mathrm{O}_{2}$ /solar light processes. Zhong et al. [41] also indicated that the degradation efficiency of tetrabromobisphenol A significantly decreased in heterogeneous UV/Fenton with the $\mathrm{H}_{2} \mathrm{O}_{2}$ concentration increasing to $20 \mathrm{mmol} / \mathrm{L}$.

3.4. Effect of $\mathrm{Fe}^{2+}$ Dosage. To investigate effect of $\mathrm{Fe}^{2+}$ dosage on COD removal, experiments were carried out at $\mathrm{Fe}^{2+}$ dosage ranging from 0 to $1.0 \mathrm{mmol} / \mathrm{L}$. Figure $3(\mathrm{c})$ showed a significant increase in COD removal efficiency from $44.5 \%$ to $77.9 \%$ with the increasing $\mathrm{Fe}^{2+}$ concentration 0 to 
$0.8 \mathrm{mmol} / \mathrm{L} . \mathrm{Fe}^{2+}$ is important for formation of photoactive ferric-hydroxo complexes that absorb UV light to produce - $\mathrm{OH}[42]$. However, further increases in $\mathrm{Fe}^{2+}$ concentration up to $0.8 \mathrm{mmol} / \mathrm{L}$ only resulted in slight increases in degradation rate. Excessive ferrous ions may act as hydroxyl radical scavenger according to the following [43]:

$$
\mathrm{Fe}^{2+}+\cdot \mathrm{OH} \longrightarrow \mathrm{Fe}^{3+}+\mathrm{OH}^{-}
$$

In addition, a deep color and high turbidity at high $\mathrm{Fe}^{2+}$ concentration reduced the transmission of UV light in solution, which inhibited the photolysis of $\mathrm{H}_{2} \mathrm{O}_{2}$ to produce $\mathrm{OH}$ radicals [31]. Therefore, overdosed $\mathrm{Fe}^{2+}$ was inefficient for COD removal by MWEUV/Fenton process.

3.5. Kinetics of COD Removal by MWEUV/Fenton. Experiments were conducted under the optimum operating conditions to evaluate the kinetics of MWEUV/Fenton degradation for pesticide-containing wastewater. A simple pseudo-first order kinetic model was used to fit experimental data and determine the kinetic parameters:

$$
\frac{-\ln C_{t}}{C_{0}}=k t,
$$

where $C_{t}$ is COD concentration $(\mathrm{mg} / \mathrm{L})$ at time $t(\mathrm{~min})$, $\mathrm{C}_{0}$ is initial COD concentration $(\mathrm{mg} / \mathrm{L})$, and $k$ is apparent rate constant $\left(\mathrm{min}^{-1}\right)$. A plot of $-\ln \left(C_{t} / C_{0}\right)$ versus $t$ generates a straight line. Apparent rate constant for the COD degradation was determined from the slope of the straight line. From Figure 4, COD degradation in MWEUV/Fenton followed pseudo-first order kinetics with rate constants $(k)$ of $0.0125 \mathrm{~min}^{-1}$ and $R^{2}$ (correlation coefficient) of 0.9171 .

3.6. Evaluation of Oxidation Degree and Mineralization. At present, two parameters, as AOS and COS, are defined to evaluate the oxidation degree and oxidative process efficiency, respectively [3]:

$$
\begin{aligned}
& \mathrm{AOS}=4-1.5\left(\frac{\mathrm{COD}_{t}}{\mathrm{DOC}_{t}}\right), \\
& \mathrm{COS}=4-1.5\left(\frac{\mathrm{COD}_{t}}{\mathrm{DOC}_{0}}\right),
\end{aligned}
$$

where $\mathrm{COD}_{t}$ is the chemical oxygen demand $(\mathrm{mg} / \mathrm{L})$ at time $t$ (min), $\mathrm{DOC}_{t}$ is the dissolved organic carbon $(\mathrm{mg} / \mathrm{L})$ at time $t$, and $\mathrm{DOC}_{0}$ is the initial dissolved organic carbon $(\mathrm{mg} / \mathrm{L})$. AOS takes values between +4 for $\mathrm{CO}_{2}$, the most oxidized state of $\mathrm{C}$, and -4 for $\mathrm{CH}_{4}$, the most reduced state of $\mathrm{C}$.

Figures 5 and 6 present the evolution of COD, DOC, AOS, and COS with reaction time. Both the initial AOS and COS parameters were -2.32 , indicating that organic compounds are at reduced state in wastewater. With the prolonging of reaction time, the concentrations of COD and DOC in wastewater gradually decreased, showing a strong oxidation of the organics. AOS and COS parameters increased to be positive, suggesting that strong mineralization occurred and highly oxidized intermediates are generated. Analyzing

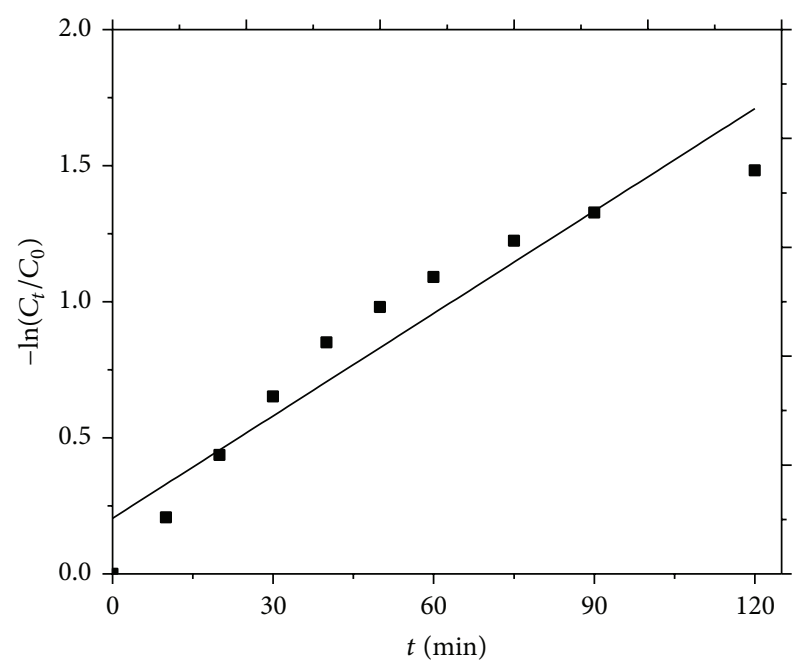

FIGURE 4: Kinetics of COD decomposition by MWEUV/Fenton. Experimental parameters: initial $\mathrm{pH}$ value of $5, \mathrm{H}_{2} \mathrm{O}_{2}$ dosage of $100 \mathrm{mmol} / \mathrm{L}$, and $\mathrm{Fe}^{2+}$ dosage of $0.8 \mathrm{mmol} / \mathrm{L}$.

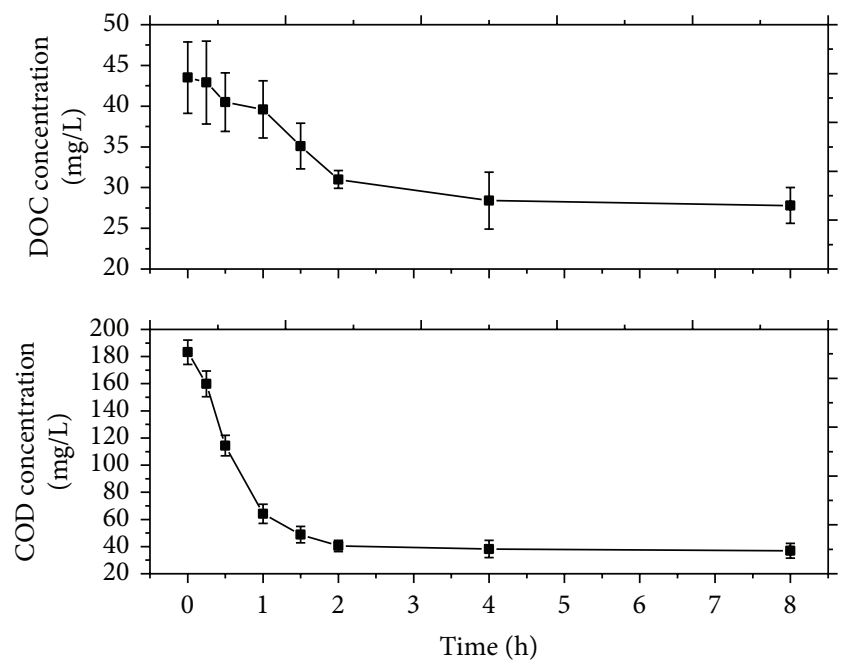

FIGURE 5: Evolution of COD and DOC in MWEUV/Fenton. Experimental parameters: initial $\mathrm{pH}$ value of $5, \mathrm{H}_{2} \mathrm{O}_{2}$ dosage of $100 \mathrm{mmol} / \mathrm{L}$, and $\mathrm{Fe}^{2+}$ dosage of $0.8 \mathrm{mmol} / \mathrm{L}$.

the different process phases, more oxidized organic intermediates were formed before $60 \mathrm{~min}$ of reaction without substantial mineralization, which is corroborated by rapid COD decrease and low DOC removal. After the gradual growth, the values of AOS and COS reached the plateau. Finally, the concentrations of COD and DOC decreased to $36.9 \mathrm{mg} / \mathrm{L}$ and $27.8 \mathrm{mg} / \mathrm{L}$, respectively, with the AOS value of 2.73 and the COS value of 2.01. The results indicate that a high oxidation degree of pesticides related to the generation of some low molecular weight carbohydrates which are resistant to mineralization by hydroxyl radicals.

The concentration profiles of Dimethoate, Triazophos, and Malathion during the MWEUV/Fenton process are shown in Figure 7. They displayed similar profiles, a rapid 


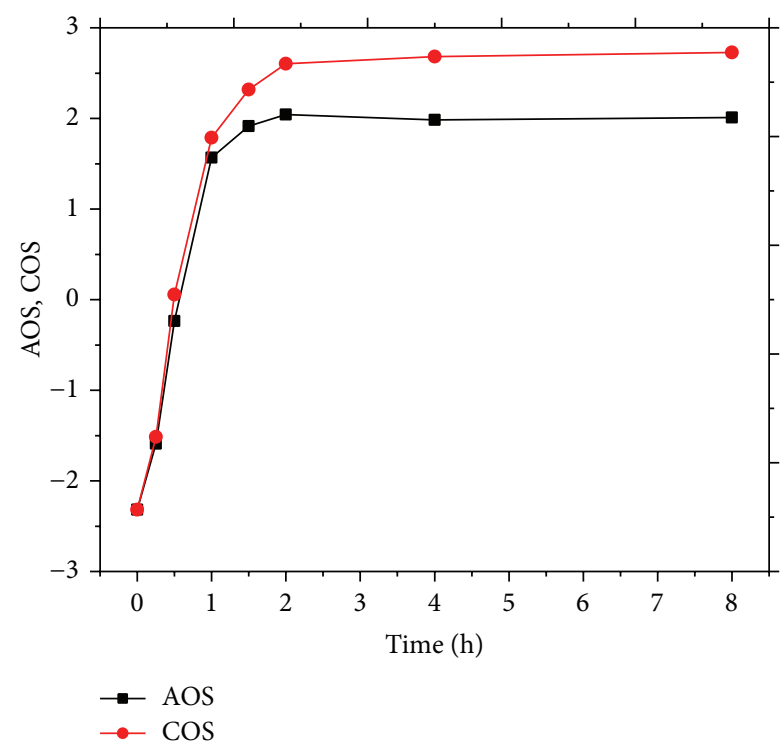

FIgURE 6: Evolution of AOS and COS in MWEUV/Fenton. Experimental parameters: initial $\mathrm{pH}$ value of $5, \mathrm{H}_{2} \mathrm{O}_{2}$ dosage of $100 \mathrm{mmol} / \mathrm{L}$, and $\mathrm{Fe}^{2+}$ dosage of $0.8 \mathrm{mmol} / \mathrm{L}$.

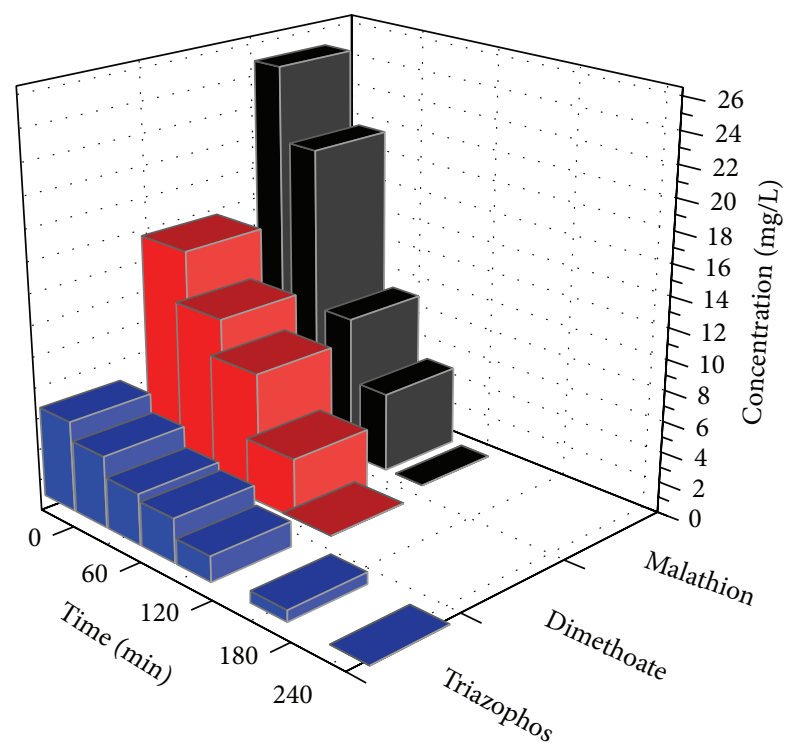

Figure 7: Degradation of Dimethoate, Triazophos, and Malathion in MWEUV/Fenton. Experimental parameters: initial $\mathrm{pH}$ value of $5, \mathrm{H}_{2} \mathrm{O}_{2}$ dosage of $100 \mathrm{mmol} / \mathrm{L}$, and $\mathrm{Fe}^{2+}$ dosage of $0.8 \mathrm{mmol} / \mathrm{L}$.

increase in pesticides concentration at the initial stage of MWEUV/Fenton process, and Dimethoate and Malathion were completely removed within $240 \mathrm{~min}$. Figure 8 exhibits the concentration changes of inorganic anions $\left(\mathrm{NO}_{3}{ }^{-}, \mathrm{SO}_{4}{ }^{2-}\right.$, and $\mathrm{PO}_{4}{ }^{3-}$ ) in the reaction. The increases of $\mathrm{SO}_{4}{ }^{2-}$ and $\mathrm{PO}_{4}{ }^{3-}$ concentration in wastewater were mainly attributed to the breakage of chemical bonds such as $\mathrm{S}=\mathrm{P}, \mathrm{P}-\mathrm{O}$, and $S-P$. The results also suggested a deep decomposition and mineralization of pesticide molecules occurring under the attack of hydroxyl radicals.

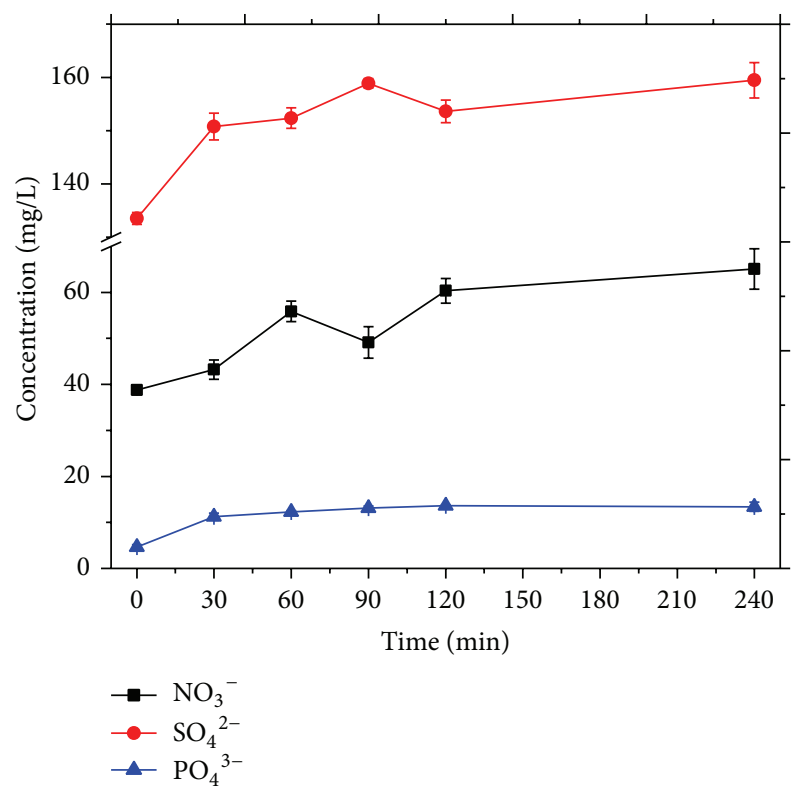

FIGURE 8: Evolution of inorganic anions in MWEUV/Fenton. Experimental parameters: initial $\mathrm{pH}$ value of $5, \mathrm{H}_{2} \mathrm{O}_{2}$ dosage of $100 \mathrm{mmol} / \mathrm{L}$, and $\mathrm{Fe}^{2+}$ dosage of $0.8 \mathrm{mmol} / \mathrm{L}$.

\section{Conclusions}

The feasibility and superiority of the MWEUV/Fenton for advanced treatment of pesticide-containing biotreated wastewater were evaluated in this paper. In terms of COD removal, the MWEUV/Fenton process showed high efficiency comparing with the conventional Fenton process assisted by commercial mercury lamps. The optimal parameters were found at the initial $\mathrm{pH}$ of $5, \mathrm{Fe}^{2+}$ dosage of $0.8 \mathrm{mmol} / \mathrm{L}$, and $\mathrm{H}_{2} \mathrm{O}_{2}$ dosage of $100 \mathrm{mmol} / \mathrm{L}$. Three main pesticides, Dimethoate, Triazophos, and Malathion, in the wastewater were completely decomposed with high oxidation and mineralization degrees.

\section{Conflict of Interests}

The authors declare that there is no conflict of interests regarding the publication of this paper.

\section{Acknowledgment}

This research was supported by Major Science and Technology Program for Water Pollution Control and Treatment (2012ZX07206-004).

\section{References}

[1] C. Zaror, C. Segura, H. Mansilla, M. A. Mondaca, and P. Gonzalez, "Kinetic study of Imidacloprid removal by advanced oxidation based on photo-Fenton process," Environmental Technology, vol. 31, no. 13, pp. 1411-1416, 2010.

[2] K. V. Plakas and A. J. Karabelas, "Removal of pesticides from water by NF and RO membranes-a review," Desalination, vol. 287, pp. 255-265, 2012. 
[3] V. J. P. Vilar, F. C. Moreira, A. C. C. Ferreira et al., "Biodegradability enhancement of a pesticide-containing biotreated wastewater using a solar photo-Fenton treatment step followed by a biological oxidation process," Water Research, vol. 46, no. 15, pp. 4599-4613, 2012.

[4] M. M. Micó, S. Chourdaki, J. Bacardit, and C. Sans, "Comparison between ozonation and photo-fenton processes for pesticide methomyl removal in advanced greenhouses," Ozone: Science \& Engineering, vol. 32, no. 4, pp. 259-264, 2010.

[5] A. Babuponnusami and K. Muthukumar, "A review on Fenton and improvements to the Fenton process for wastewater treatment," Journal of Environmental Chemical Engineering, vol. 2, no. 1, pp. 557-572, 2014.

[6] M. J. Benotti, B. D. Stanford, E. C. Wert, and S. A. Snyder, "Evaluation of a photocatalytic reactor membrane pilot system for the removal of pharmaceuticals and endocrine disrupting compounds from water," Water Research, vol. 43, no. 6, pp. 15131522, 2009.

[7] N. Klamerth, S. Malato, A. Agüera, A. Fernández-Alba, and G. Mailhot, "Treatment of municipal wastewater treatment plant effluents with modified photo-fenton as a tertiary treatment for the degradation of micro pollutants and disinfection," Environmental Science \& Technology, vol. 46, no. 5, pp. 28852892, 2012.

[8] Q.-F. Zeng, J. Fu, Y. Zhou, Y.-T. Shi, and H.-L. Zhu, "Photooxidation degradation of Reactive brilliant red K-2BP in aqueous solution by ultraviolet radiation/sodium hypochlorite," Clean: Soil, Air, Water, vol. 37, no. 7, pp. 574-580, 2009.

[9] Y. Deng and J. D. Englehardt, "Treatment of landfill leachate by the Fenton process," Water Research, vol. 40, no. 20, pp. 36833694, 2006.

[10] C. Orbeci, I. Untea, G. Nechifor, A. E. Segneanu, and M. E. Craciun, "Effect of a modified photo-Fenton procedure on the oxidative degradation of antibiotics in aqueous solutions," Separation and Purification Technology, vol. 122, pp. 290-296, 2014.

[11] M. Umar, H. A. Aziz, and M. S. Yusoff, "Trends in the use of Fenton, electro-Fenton and photo-Fenton for the treatment of landfill leachate," Waste Management, vol. 30, no. 11, pp. 21132121, 2010.

[12] J. X. Chen and L. Z. Zhu, "Oxalate enhanced mechanism of hydroxyl-Fe-pillared bentonite during the degradation of Orange II by UV-Fenton process," Journal of Hazardous Materials, vol. 185, no. 2-3, pp. 1477-1481, 2011.

[13] A. Karci, I. Arslan-Alaton, T. Olmez-Hanci, and M. Bekbölet, "Transformation of 2,4-dichlorophenol by $\mathrm{H}_{2} \mathrm{O}_{2} / \mathrm{UV}-\mathrm{C}$, Fenton and photo-Fenton processes: oxidation products and toxicity evolution," Journal of Photochemistry and Photobiology A: Chemistry, vol. 230, no. 1, pp. 65-73, 2012.

[14] A. Karci, I. Arslan-Alaton, M. Bekbolet, G. Ozhan, and B. Alpertunga, " $\mathrm{H}_{2} \mathrm{O}_{2} / \mathrm{UV}-\mathrm{C}$ and Photo-Fenton treatment of a nonylphenol polyethoxylate in synthetic freshwater: followup of degradation products, acute toxicity and genotoxicity," Chemical Engineering Journal, vol. 241, pp. 43-51, 2014.

[15] J. Fu, Z. Xu, Q.-S. Li et al., "Treatment of simulated wastewater containing Reactive Red 195 by zero-valent iron/activated carbon combined with microwave discharge electrodeless lamp/sodium hypochlorite," Journal of Environmental Sciences, vol. 22 , no. 4 , pp. $512-518,2010$.

[16] J. Fu, T. Wen, Q. Wang et al., "Degradation of Active Brilliant Red X-3B by a microwave discharge electrodeless lamp in the presence of activated carbon," Environmental Technology, vol. 31, no. 7, pp. 771-779, 2010.

[17] A. I. Al-Shamma’a, I. Pandithas, and J. Lucas, "Low-pressure microwave plasma ultraviolet lamp for water purification and ozone applications," Journal of Physics D: Applied Physics, vol. 34, no. 18, pp. 2775-2781, 2001.

[18] J. H. Xu, C. L. Li, P. Liu, D. He, J. F. Wang, and Q. Zhang, "Photolysis of low concentration $\mathrm{H}_{2} \mathrm{~S}$ under UV/VUV irradiation emitted from high frequency discharge electrodeless lamps," Chemosphere, vol. 109, pp. 202-207, 2014.

[19] S. Horikoshi, M. Kajitani, S. Sato, and N. Serpone, "A novel environmental risk-free microwave discharge electrodeless lamp (MDEL) in advanced oxidation processes. Degradation of the 2,4-D herbicide," Journal of Photochemistry and Photobiology A: Chemistry, vol. 189, no. 2-3, pp. 355-363, 2007.

[20] X. Zhang, Y. Wang, G. Li, and J. Qu, "Oxidative decomposition of azo dye C.I. Acid Orange 7 (AO7) under microwave electrodeless lamp irradiation in the presence of $\mathrm{H}_{2} \mathrm{O}_{2}$, Journal of Hazardous Materials, vol. 134, no. 1-3, pp. 183-189, 2006.

[21] C. Ferrari, I. Longo, E. Tombari, and E. Bramanti, "A novel microwave photochemical reactor for the oxidative decomposition of Acid Orange 7 azo dye by $\mathrm{MW} / \mathrm{UV} / \mathrm{H}_{2} \mathrm{O}_{2}$ process," Journal of Photochemistry and Photobiology A: Chemistry, vol. 204, no. 2-3, pp. 115-121, 2009.

[22] J. Hong, C. Sun, S.-G. Yang, and Y.-Z. Liu, "Photocatalytic degradation of methylene blue in $\mathrm{TiO}_{2}$ aqueous suspensions using microwave powered electrodeless discharge lamps," Journal of Hazardous Materials, vol. 133, no. 1-3, pp. 162-166, 2006.

[23] S. Horikoshi, M. Kajitani, N. Horikoshi, R. Dillert, and D. W. Bahnemann, "Use of microwave discharge electrodeless lamps (MDEL). II. Photodegradation of acetaldehyde over $\mathrm{TiO}_{2}$ pellets," Journal of Photochemistry and Photobiology A: Chemistry, vol. 193, no. 2-3, pp. 284-287, 2008.

[24] S. Horikoshi, H. Hidaka, and N. Serpone, "Environmental remediation by an integrated microwave/UV-illumination technique IV. Non-thermal effects in the microwave-assisted degradation of 2,4-dichlorophenoxyacetic acid in UVirradiated $\mathrm{TiO}_{2} / \mathrm{H}_{2} \mathrm{O}$ dispersions," Journal of Photochemistry and Photobiology A: Chemistry, vol. 159, no. 3, pp. 289-300, 2003.

[25] X. W. Zhang, G. T. Li, Y. Z. Wang, and J. H. Qu, "Microwave electrodeless lamp photolytic degradation of acid orange 7," Journal of Photochemistry and Photobiology A: Chemistry, vol. 184, no. 1-2, pp. 26-33, 2006.

[26] APHA, Standard Methods for the Examination of Water and Wastewater, American Public Health Association, Washington, DC, USA, 21st edition, 2005.

[27] X. W. Zhang, G. T. Li, and Y. Z. Wang, "Microwave assisted photocatalytic degradation of high concentration azo dye Reactive Brilliant Red X-3B with microwave electrodeless lamp as light source," Dyes and Pigments, vol. 74, no. 3, pp. 536-544, 2007.

[28] D.-H. Han, S.-Y. Cha, and H.-Y. Yang, "Improvement of oxidative decomposition of aqueous phenol by microwave irradiation in $\mathrm{UV} / \mathrm{H}_{2} \mathrm{O}_{2}$ process and kinetic study," Water Research, vol. 38, no. 11, pp. 2782-2790, 2004.

[29] Y.-Y. Zhang, C. He, V.-K. Sharma, X.-Z. Li, S.-H. Tian, and Y. Xiong, "A new reactor coupling heterogeneous Fenton-like catalytic oxidation with membrane separation for degradation of organic pollutants," Journal of Chemical Technology and Biotechnology, vol. 86, no. 12, pp. 1488-1494, 2011.

[30] J.-H. Park, I.-H. Cho, and S.-W. Chang, "Comparison of Fenton and Photo-Fenton processes for livestock wastewater 
treatment," Journal of Environmental Science and Health Part B Pesticides, Food Contaminants, and Agricultural Wastes, vol. 41, no. 2, pp. 109-120, 2006.

[31] J. Rodríguez-Chueca, M. I. Polo-López, R. Mosteo, M. P. Ormad, and P. Fernández-Ibáñez, "Disinfection of real and simulated urban wastewater effluents using a mild solar photoFenton," Applied Catalysis B: Environmental, vol. 150-151, pp. 619-629, 2014.

[32] Q. Wang, S. Tian, J. Long, and P. Ning, "Use of Fe(II)Fe(III)LDHs prepared by co-precipitation method in a heterogeneousFenton process for degradation of Methylene Blue," Catalysis Today, vol. 224, pp. 41-48, 2014.

[33] M. Siddique, R. Farooq, and G. J. Price, "Synergistic effects of combining ultrasound with the Fenton process in the degradation of Reactive Blue 19," Ultrasonics Sonochemistry, vol. 21, no. 3, pp. 1206-1212, 2014.

[34] M. Neamtu, A. Yediler, I. Siminiceanu, and A. Kettrup, "Oxidation of commercial reactive azo dye aqueous solutions by the photo-Fenton and Fenton-like processes," Journal of Photochemistry and Photobiology A: Chemistry, vol. 161, no. 1, pp. 87-93, 2003.

[35] P. K. Malik and S. K. Saha, "Oxidation of direct dyes with hydrogen peroxide using ferrous ion as catalyst," Separation and Purification Technology, vol. 31, no. 3, pp. 241-250, 2003.

[36] M. I. Badawy, F. E. Gohary, M. Y. Ghaly, and M. E. M. Ali, "Enhancement of olive mill wastewater biodegradation by homogeneous and heterogeneous photocatalytic oxidation," Journal of Hazardous Materials, vol. 169, no. 1-3, pp. 673-679, 2009.

[37] P. V. Nidheesh, R. Gandhimathi, and S. T. Ramesh, "Degradation of dyes from aqueous solution by Fenton processes: a review," Environmental Science and Pollution Research, vol. 20, no. 4, pp. 2099-2132, 2013.

[38] W. Sabaikai, M. Sekine, M. Tokumura, and Y. Kawase, "UV light photo-Fenton degradation of polyphenols in oolong tea manufacturing wastewater," Journal of Environmental Science and Health Part A: Toxic/Hazardous Substances and Environmental Engineering, vol. 49, no. 2, pp. 193-202, 2014.

[39] W. G. Li, Y. Wang, and A. Irini, "Effect of $\mathrm{pH}$ and $\mathrm{H}_{2} \mathrm{O}_{2}$ dosage on catechol oxidation in nano- $\mathrm{Fe}_{3} \mathrm{O}_{4}$ catalyzing UV-Fenton and identification of reactive oxygen species," Chemical Engineering Journal, vol. 244, pp. 1-8, 2014.

[40] M. S. Lucas and J. A. Peres, "Degradation of reactive black 5 by Fenton/UV-C and ferrioxalate/ $\mathrm{H}_{2} \mathrm{O}_{2}$ /solar light processes," Dyes and Pigments, vol. 74, no. 3, pp. 622-629, 2007.

[41] Y. H. Zhong, X. L. Liang, Y. Zhong et al., "Heterogeneous UV/Fenton degradation of TBBPA catalyzed by titanomagnetite: catalyst characterization, performance and degradation products," Water Research, vol. 46, no. 15, pp. 4633-4644, 2012.

[42] N. Ayten, I. Arslan-Alaton, and T. Ölmez-Hanci, "Application of Photo-Fenton-like oxidation for the degradation and detoxification of commercial naphthalene sulfonates a case study with $\mathrm{H}$-acid model pollutant," Desalination and Water Treatment, vol. 26, no. 1-3, pp. 139-144, 2011.

[43] D. Vujević, S. Papić, N. Koprivanac, and A. L. Božić, "Decolorization and mineralization of reactive dye by UV/Fenton process," Separation Science and Technology, vol. 45, no. 11, pp. 1637-1643, 2010. 

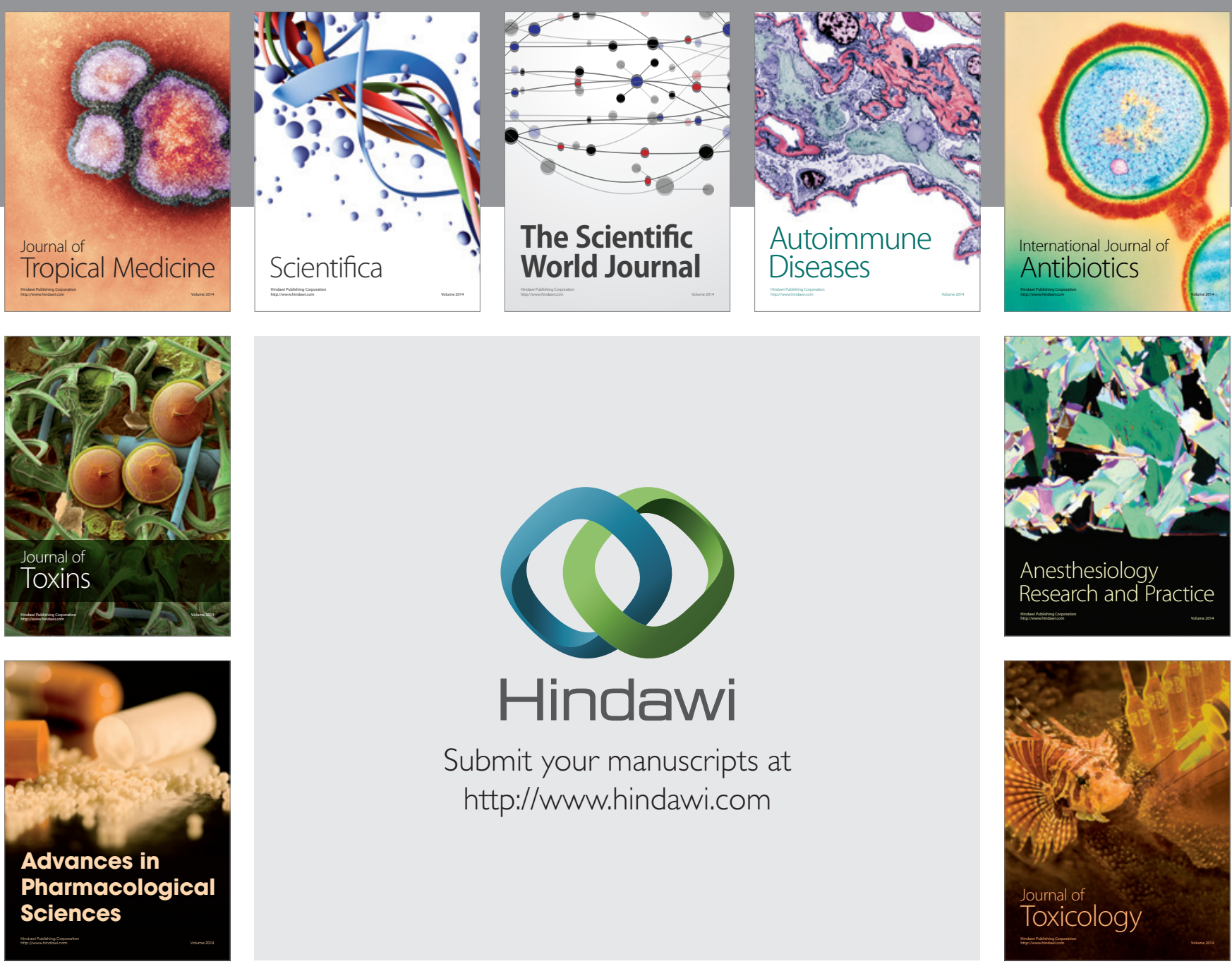

\section{Hindawi}

Submit your manuscripts at

http://www.hindawi.com
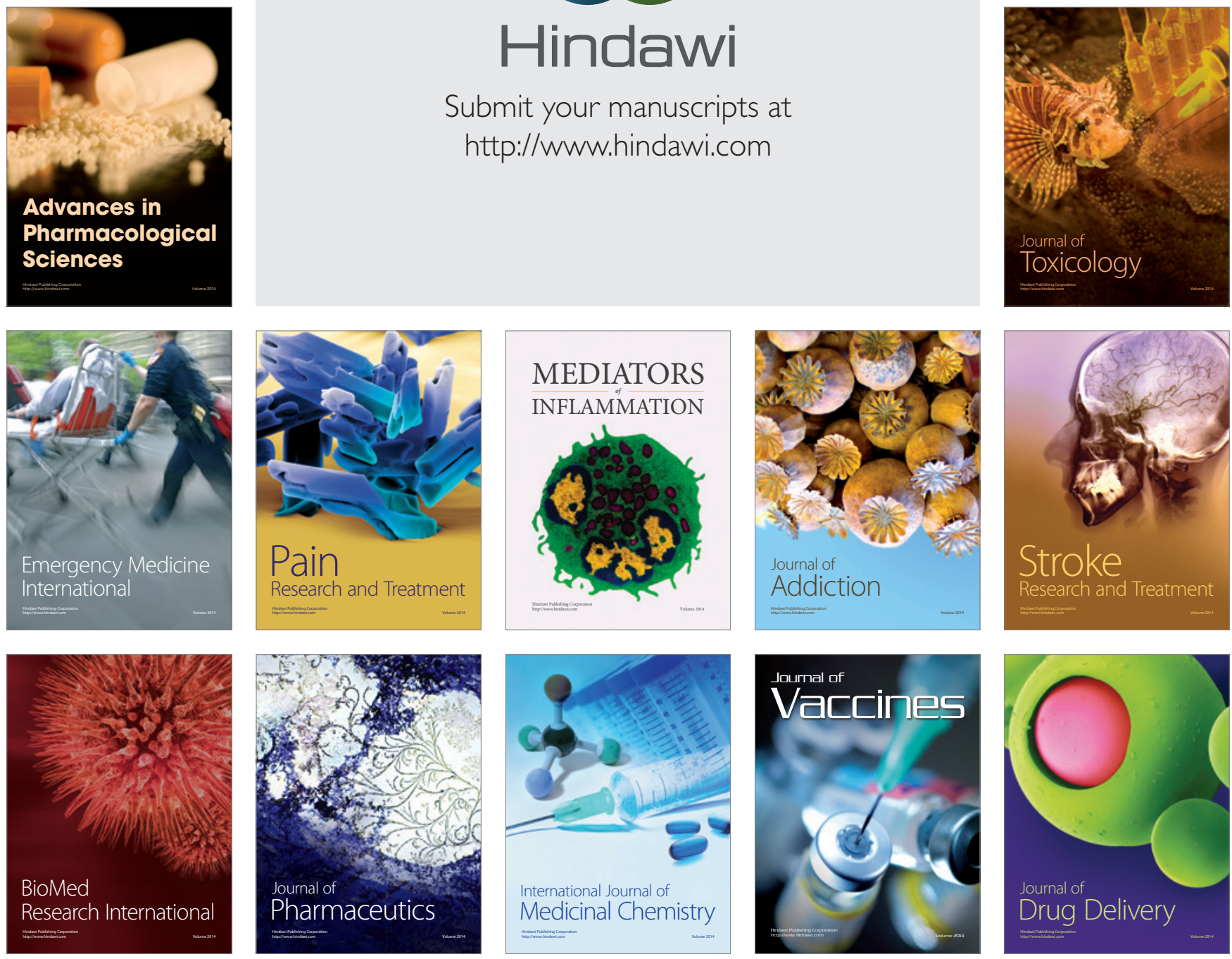